\title{
Thermo-Fluidic Modelling of a Heat Exchanger Tube with Conical Shaped Insert having Protrusion and Dimple Roughness
}

\author{
Bhanu Pratap Singh ${ }^{1}$, Vijay Singh Bisht ${ }^{2}$, Prabhakar Bhandari ${ }^{3}$, K.S. Rawat ${ }^{3}$ \\ ${ }^{1}$ Tulas Institute, Uttarakhand Technical University, Dehradun 248007, India \\ ${ }^{2}$ Faculty of Technology, Uttarakhand Technical University, Dehradun 248007, India \\ ${ }^{3}$ NIT Uttarakhand, Srinagar Garhwal 246174, India \\ ${ }^{4}$ MIET, Meerut-250005, India \\ e-mail: bps@nplindia.org ${ }^{1}$, vsinghbisht5@gmail.com² ${ }^{2}$, prabhakar.bhandari40@gmail.com ${ }^{3}$, \\ kamal.rawat@miet.ac.in ${ }^{5}$
}

To cite this document:

Singh, B. P. ., Bisht, V. S. ., Bhandari, P. ., \& rawat, kamal. (2021). Thermo-Fluidic Modelling of a Heat Exchanger Tube with Conical Shaped Insert having Protrusion and Dimple Roughness. Aptisi Transactions on Technopreneurship (ATT), 3(2), 13-29.

DOI: https://doi.org/10.34306/att.v3i2.200

\begin{abstract}
In the context of energy, an efficient heat exchanger is always desired. In the present work, thermo-fluidic behavior of a heat exchanger tube with conical shaped insert has been investigated with the help of finite volume method. To enhance the heat transfer rate, two different types of roughness have been used in conical insert i.e. protrusion and dimple roughness. A three-dimensional computational model with $k-\varepsilon$ RNG turbulence model is used for the simulation and it has been performed for three different diameters $(3 \mathrm{~mm}, 6 \mathrm{~mm}$ and 9 $\mathrm{mm}$ ) and two different pitch space $(120 \mathrm{~mm}$ and $180 \mathrm{~mm})$ for both protrusion and dimple roughness. The present model has been validated with Dittus-Boelter equation and with Blasius equation for Nusselt number and friction factor, respectively. For a constant heat flux of $1200 \mathrm{~W} / \mathrm{m} 2$, effect of roughness, diameter and pitch on Nusselt number and friction factor has been predicted for Reynold number range of 5000 to 30000 . From the result, it is found that the protrusion shaped roughness has better thermal performance factor than dimple shape and diameter of $6 \mathrm{~mm}$ has performed better than $3 \mathrm{~mm}$ and $9 \mathrm{~mm}$ for both the cases of roughness due to favorable flow dynamics.
\end{abstract}

Keywords: Computational fluid dynamics, Heat Exchanger, Conical insert, Dimple shaped roughness, Protrusion roughness.

\section{Introduction}

With the increase in the world population, energy crises become a global problem which has also a direct impact on the environmental and economic problems for a country. There is a large-scale consumption of thermal energy in distinct industries viz. chemical, HVAC, power, solar, manufacturing, food processing and, etc. Therefore, there must be an efficient use of thermal energy in these industries. The most common part in above mentioned industries is a heat exchanger, which is used to transfer heat between the fluids. A better design for this component leads to good thermal efficiency and provides economical and environment gains [1-3]. Therefore, lots of researchers are working on methods of heat transfer enhancement for a heat exchanger. The passive method has gained sufficient attention in recent years and there are continuous efforts in this direction to design a more 
compact and energy efficient heat exchanger. In passive methods, a local turbulence is created by the modification in the geometry of the heat exchanger to enhance the heat transfer [4].

The passive techniques include surface treatment i.e. Hydrophobic and Hydrophilic surface, roughened the surfaces, use of extended surfaces like fins and inserts, introduction of devices like displaced enhancement devices and vortex generation devices. Other methods are also used by researchers like introducing foreign elements in the coolant like nano fluids [5] and using phase change material, etc.

There are various inserts used by various researchers for heat transfer augmentation in heat exchangers. ThianPong et al. [6] uses insert in the form of twisted tape having perforations (PTT) in their study for heat transfer rate improvement. This insert was placed inside the heat exchanger tube. The perforated twisted tapes are constructed by making a series of holes in the tape throughout the tape length. The heat transfer rate has been significantly increased using PTT and enhancement of about $36-85 \%$ was observed over the tube without PTT i.e. plain tube. It was also concluded by them that decreasing the pitch ratio and twisted tape ratio leads to heat transfer rate increment. Eiamsa-ard [7] instead of single twisted tape, uses Multiple Twisted tape in their work. The term Multiple Twisted tape means that the heat exchanger tube can hold two, three and four twisted tape together in it to achieve better thermal performance. He concluded that multiple twisted tapes were having thermal performance factors higher than that of single twisted tape and about $0.94-1.4 \%$ increment in efficiency.

Murugesan et al. [8] also uses twisted tape insert but these inserts are having trapezoidal cuts. They observe significant enhancement in heat transfer rate. Murugesan et al. [9] also performed similar work using $U$ cut twisted tape insert. They found that $U$ cut twisted tape is having thermal enhancement of 1.22 for twist ratio of 2.0. They concluded that $U$ cut twisted tape is much more beneficial than plain twisted tape.

Promvonge [10] conducted an experimental study on heat exchanger having both wire coil and twisted tape inside the tube. The wire was around the twisted tape along its full length and this combination is inside of the heat exchanger tube so that swirl flow can be generated in the tube. The use of wire coil and twisted tape together has efficiency approximately double of twisted tape alone. Eiamsa-ard et al [11] also studies similar design but with variable pitch of the coil. They observed that decreasing/increasing coil pitch arrangement has given highest efficiency. Arulprakasam Jothi et al. [12] uses conical strip inserts inside the circular tube as turbulators. They use conical strips with variable twist ratio in staggered and non-staggered arrangement. . In their study it was found that staggered arrangement of conical strips having twist ratio of 3 has the highest value of Nusselt number. Based on their study, they also provide correlations for Nusselt number and friction factor

The Introduction should provide a clear background, a clear statement of the problem, the relevant literature on the subject, the proposed approach or solution, and the new value of research which is innovation. It should be understandable to colleagues from a broad range of scientific disciplines [5].

Durmus [13] studies the effect of a cut out conical turbulator in the heat exchanger tube. He concluded that these turbulators were placed directly in fluid flow, because of that there was increase in Nusselt number accompanied with increase in pressure drop. He also studies the effect of turbulator angle and observed that both Nusselt number and friction factor increases with turbulator angle. Different types of inserts used in heat exchangers are shown in Fig.1.

Promvonge and Eiamsa-ard [14] uses conical-ring and twisted-tape insert in a circular tube and concluded that this combination has over $10 \%$ enhancement in heat transfer rate from conical- ring alone case. Promvonge [15] uses a heat exchanger tube fitted with a conical ring. In his experimental work, he uses arrays of conical ring turbulator. Three different types of conical ring turbulator used by him were: Converging conical ring (CR), Diverging conical ring (DR) and Converging-Diverging conical ring (CDR). He also varies the diameter ratio (ring diameter/tube diameter) from 0.5-0.7. He found that the enhancement efficiency was maximum for diameter ratio of 0.5 for all three arrays. He also concluded that DR array has 
highest efficiency, CR has least and while CDR has in between them. Sketches of different inserts used in heat exchangers have been compiled in Fig. 1. Many researchers [14, 15, 18] have performed studies on conical turbulator inserts in the heat exchanger tube for improvement of heat transfer rate and hot shortness problem.

To further enhance the performance of heat exchanger having conical turbulator, two different types of roughness have been investigated. The roughness is implemented in the present study are:

1. Conical ring with protrusion roughness

2. Conical ring with dimple roughness.

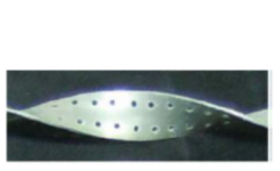

(a)

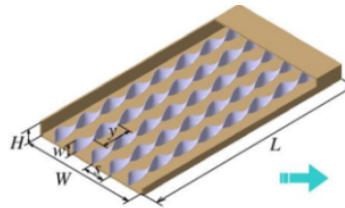

(b)

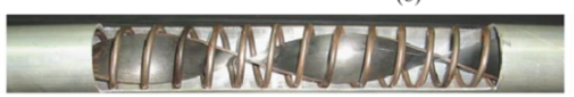

(d)

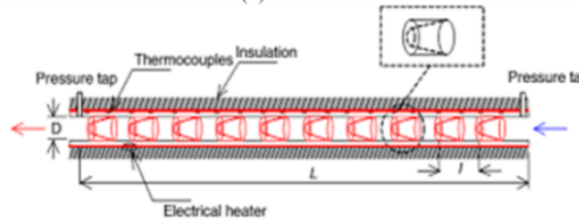

(f)

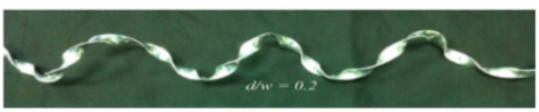

(h)

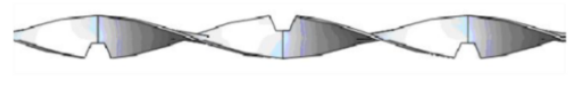

(c)

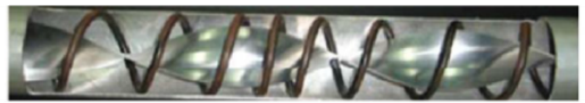

(e)

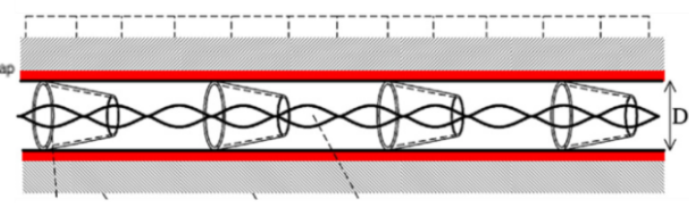

(g)

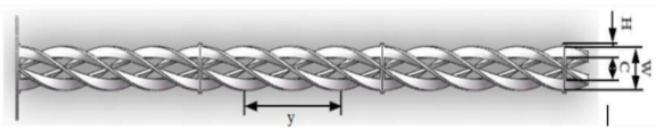

(i)

Fig 1. Sketch of various configurations of inserts used in heat exchanger tube (a) Perforated twisted tape [6] (b) Multiple twisted tape [7] (c) Trapezoidal cut twisted tape Triangular [8] (d)Uniform wire coil twisted tape [10] (e) Non uniform coil twisted tape [11] (f) Conical shaped inserts [12] (g) Conical ring turbulator with twisted tape [14] (h) Perforated helical twisted tape [16] (i) Cross hollow twisted tape [17]

\section{Modelling}

In present work, a heat exchanger tube with conical insert has been analyzed numerically. The present heat exchanger tube has been investigated with protrusion and dimple roughness on the inner part of the conical insert. For the solution of the present problem, flow equations with $k-\varepsilon$ RNG turbulence model and energy equation are solved using Fluent V14.0.

\subsection{Formula/Algorithm [optional]}

In this work, a $1500 \mathrm{~mm}$ long, circular cross-sectional tube with $30 \mathrm{~mm}$ inner diameter and $5 \mathrm{~mm}$ thickness is considered. For the investigation, the tube length has been divided into three sections which are entrance, test and exit sections, respectively. The 2D schematic diagram of the tube with different three sections is shown in fig.2 (a). The length of entrance and exit sections are $100 \mathrm{~mm}$ and the test section in which conical rings with roughness are placed, is $1300 \mathrm{~mm}$ long. All the conical inserts are oriented along the flow direction and have the same size. The dimension of conical insert is defined with the help of base radius, top radius and length which are 15,12 and $40 \mathrm{~mm}$, respectively. The cone shaped inserts are 
roughened through inside, having protrusion and dimple roughness in fig. $3 \& 4$, respectively. This conical ring roughness helps in heat transfer augmentation between tube surface and working fluid because of formation of turbulent eddies in the tube and disturbances in the boundary layer. Therefore, to know the effect of roughness size on the flow and heat transfer, both the roughness with diameters of 3,6 and $9 \mathrm{~mm}$ are considered. Details of the present numerical model are tabulated in Table 1.

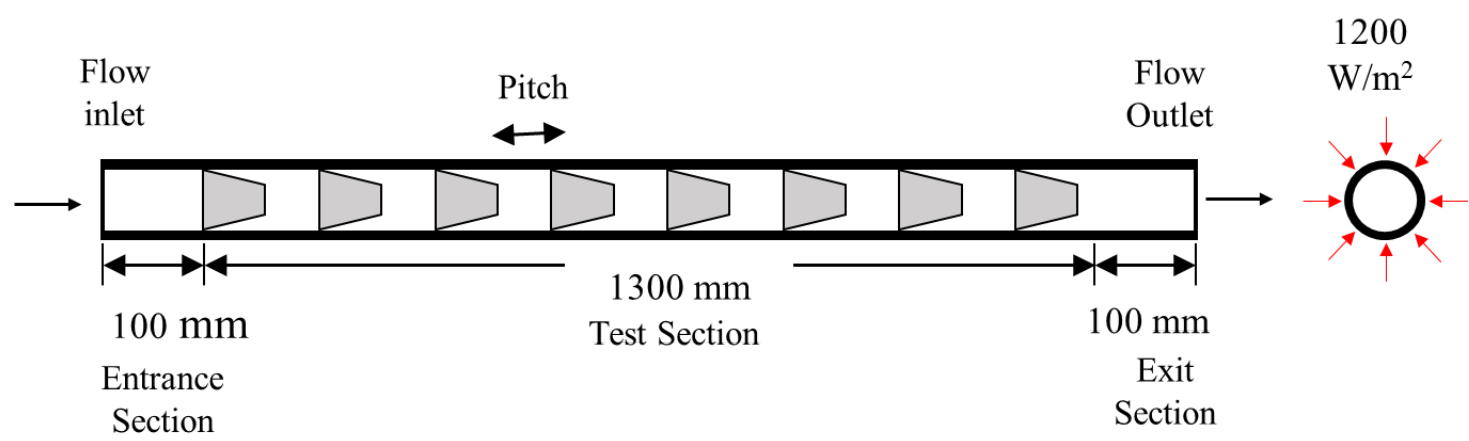

(a)

(b)

Fig 2. Schematic diagram of the tube (a) view along the longitudinal axis (b) cross- sectional view

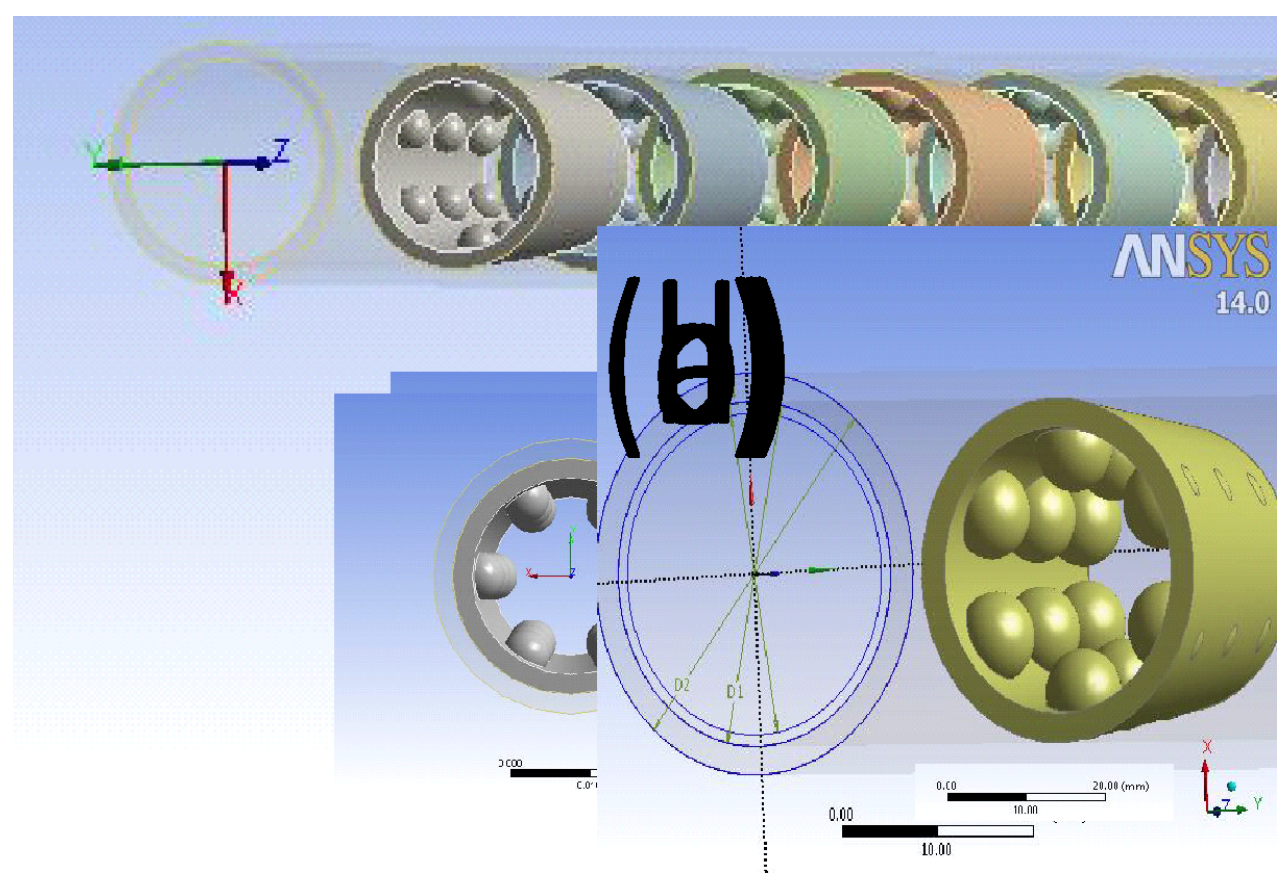

Fig 3.: (a) Three-dimensional geometry of conical insert roughened with protrusion (b) protrusion diameter $\mathrm{d}=3 \mathrm{~mm}$ (c) $\mathrm{d}=6 \mathrm{~mm}$ (d) $\mathrm{d}=9 \mathrm{~mm}$ 
(b)
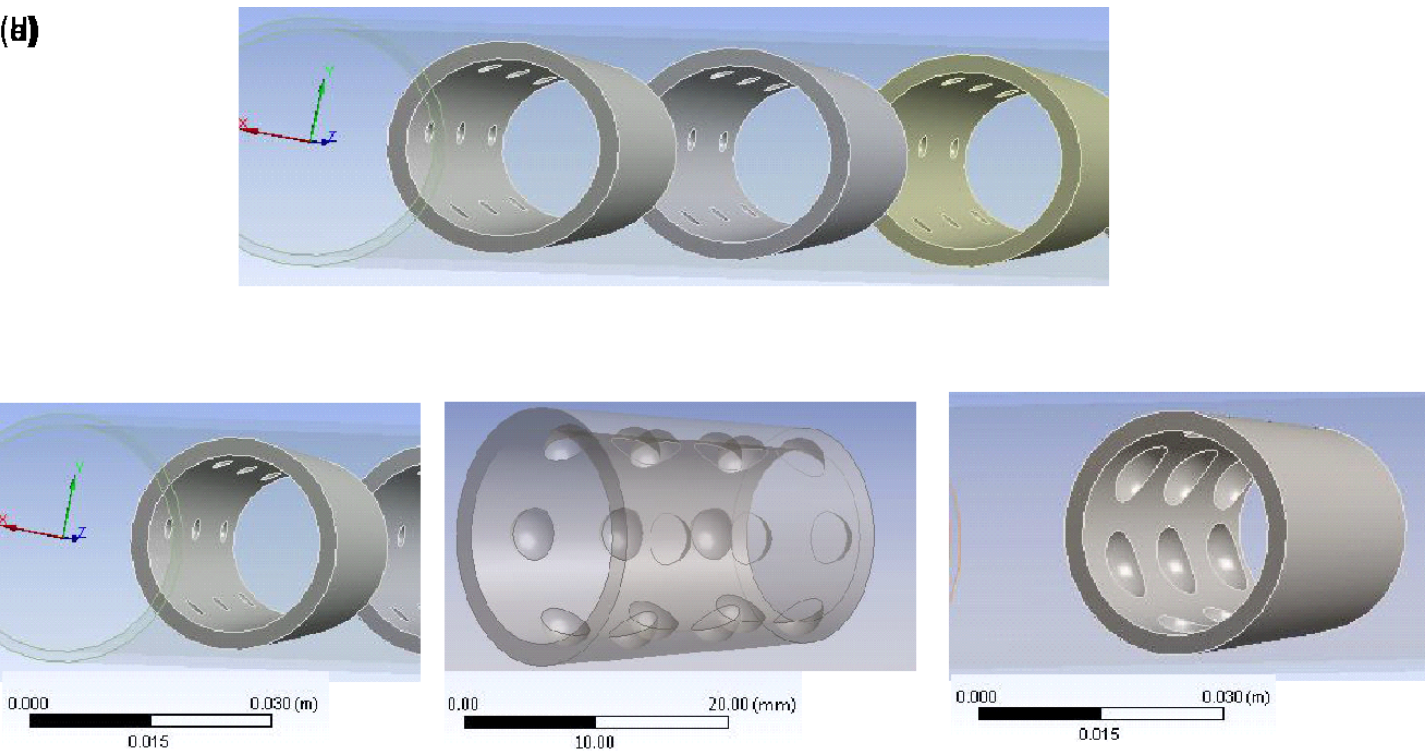

Fig 4. (a) Three-dimensional geometry of conical insert roughened with dimple (b) dimple diameter $\mathrm{d}=3 \mathrm{~mm}$ (c) $\mathrm{d}=6 \mathrm{~mm}$ (d) $\mathrm{d}=9 \mathrm{~mm}$

Table 1: Details of different geometric and working parameters of the present heat exchanger tube model

\begin{tabular}{rll}
\hline S. No. & Parameters & Values \\
\hline 1. & Cone base radius of cone & $15 \mathrm{~mm}$ \\
& Cone top radius of cone & $12 \mathrm{~mm}$ \\
& Cone length of the cone & $40 \mathrm{~mm}$ \\
2. & Thickness of the cone roughness & $2.5 \mathrm{~mm}$ \\
3. & Diameters of the Protrusion and Dimple shape, d & $3 \mathrm{~mm}, 6 \mathrm{~mm}$, and $9 \mathrm{~mm}$ \\
4. & Space between the roughness on cone & at $72^{\circ}$ \\
5. & Relative Roughness Pitch to hydraulic diameter ratio or pitch ratio,, & PR $=4$, and 8 \\
& PR & \\
6. Hydraulic Diameter, $\mathrm{D}_{\mathrm{h}}$ of Water Tube used & $30 \mathrm{~mm}$ \\
7. & Pitch space between the insert roughness as cone, P & $120 \mathrm{~mm}$, and $180 \mathrm{~mm}$ \\
8. & Uniform Heat Flux, $\mathrm{I}$ & $1200 \mathrm{w} / \mathrm{m}^{2}$ \\
9. & Reynolds Number, Re & 5000 to 30000 \\
10. & Prandtl Number, Pr & 0.707 \\
\hline
\end{tabular}

\subsection{Mathematical Model}

The mathematical model has been developed based on a finite volume approach. The governing equations for an element control volume are as follows . 
Continuity equation.

$$
\frac{\partial \vec{u}}{\partial x}+\frac{\partial \vec{v}}{\partial y}+\frac{\partial \vec{w}}{\partial z}=0
$$

\section{Momentum equation}

$$
\begin{aligned}
& \left(\vec{u} \frac{\partial \vec{u}}{\partial x}+\vec{v} \frac{\partial \vec{u}}{\partial y}+\vec{w} \frac{\partial \vec{u}}{\partial z}\right)=-\frac{1}{\varrho} \frac{\partial p}{\partial x}+v\left(\frac{\partial^{2} \vec{u}}{\partial x^{2}}+\frac{\partial^{2} \vec{u}}{\partial y^{2}}+\frac{\partial^{2} \vec{u}}{\partial z^{2}}\right) \\
& \text { (2) }\left(\vec{u} \frac{\partial \vec{v}}{\partial x}+\vec{v} \frac{\partial \vec{v}}{\partial y}+\vec{w} \frac{\partial \vec{v}}{\partial z}\right)=-\frac{1}{\varrho} \frac{\partial p}{\partial y}+v\left(\frac{\partial^{2} \vec{v}}{\partial x^{2}}+\frac{\partial^{2} \vec{v}}{\partial y^{2}}+\frac{\partial^{2} \vec{v}}{\partial z^{2}}\right) \\
& \left(\vec{u} \frac{\partial \vec{v}}{\partial x}+\vec{v} \frac{\partial \vec{v}}{\partial y}+\vec{w} \frac{\partial \vec{v}}{\partial z}\right)=-\frac{1}{\varrho} \frac{\partial p}{\partial z}+v\left(\frac{\partial^{2} \vec{v}}{\partial x^{2}}+\frac{\partial^{2} \vec{v}}{\partial y^{2}}+\frac{\partial^{2} \vec{v}}{\partial z^{2}}\right)
\end{aligned}
$$

\section{Energy equation}

$$
\vec{u} \frac{\partial t}{\partial x}+\vec{v} \frac{\partial t}{\partial y}+\vec{w} \frac{\partial t}{\partial y}=\alpha\left(\frac{\partial^{2} t}{\partial x^{2}}+\frac{\partial^{2} t}{\partial y^{2}}+\frac{\partial^{2} t}{\partial y^{2}}\right)
$$

\begin{tabular}{|c|c|c|c|}
\hline S. No & Properties & Value & Unit \\
\hline \multicolumn{4}{|c|}{ Copper } \\
\hline 1 & Density, $\rho$ & 8978 & $\mathrm{~kg} / \mathrm{m}^{3}$ \\
\hline 2 & Specific heat c & 381 & $\mathrm{~J} / \mathrm{kg}-\mathrm{K}$ \\
\hline 3 & Thermal conductivity $\mathrm{k}$ & 387.6 & \\
\hline \multicolumn{4}{|c|}{ 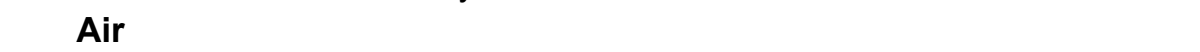 } \\
\hline 4 & Density $(\rho)$ & 1.225 & $\mathrm{~kg} / \mathrm{m}^{3}$ \\
\hline 5 & Specific heat c & 1006.4 & $\mathrm{~J} / \mathrm{kg}-\mathrm{K}$ \\
\hline 6 & Viscosity $(\mu)$ & 0.000017894 & \\
\hline 7 & Thermal conductivity $\mathrm{k}$ & 0.707 & \\
\hline
\end{tabular}

In this study, the heat exchanger tube and different inserts are made of copper. As it has good thermal conductivity, good strength in elevated temperature and minimum thermal gradient. The thermo-physical properties of copper \& air has been given in Table 2 .

Table 2. Properties of copper and air

\subsection{Mesh Discretization and Grid independence Test}

The present model has two computational domains i.e. solid substrate and fluid flow region. A complete computational domain has been shown in Fig. 5(a). In present work, two 
different methods have been opted for discretization. Outside of the tube, coarser meshing has been used while inside of the tube, fine meshing has been opted. The meshed figure of a conical ring roughened by dimple and protrusion roughness is shown in Fig. 5 (b) and Fig. $5(c)$.

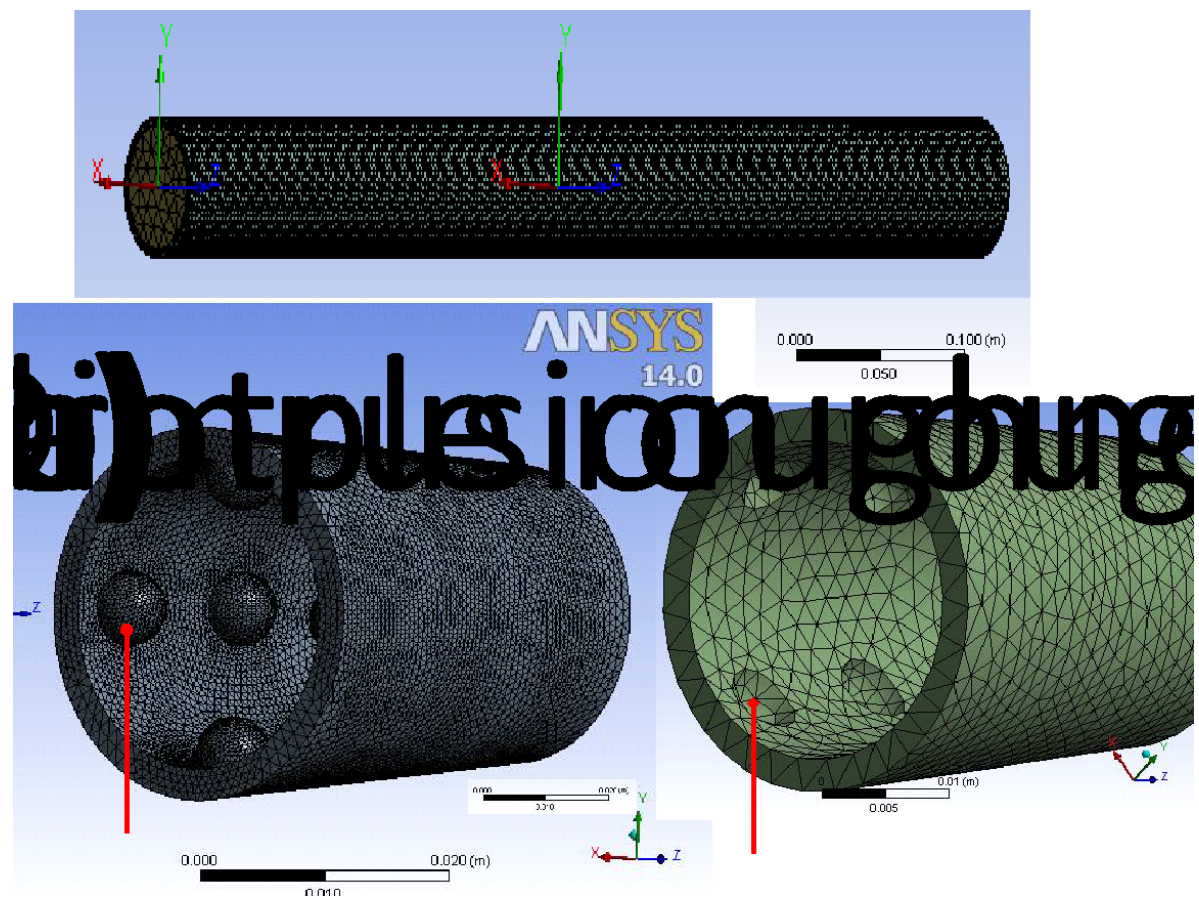

Fig 5.Meshing of the present model (a) Whole computation domain (b) Conical insert roughened with dimple (c) Conical insert roughened with protrusion

The grid independence test has been performed and the details of the test are tabulated in Table 3. Four sets of cases were performed in a grid independence test with a variable number of elements. It was observed that after the 1207624 numbers of elements, the Nusselt number does not increase much. Hence, in all simulations similar grid size has been used.

Table 3. Grid independence test for Heat transfer tube with conical roughness

\begin{tabular}{|l|l|l|l|l|}
\hline Case & Case 1 & Case 2 & Case 3 & Case 4 \\
\hline Number of Elements & 37112 & 128432 & 1207624 & 1390330 \\
\hline Nusselt Number & 12.67 & 30.52 & 36.05 & 36.99 \\
\hline
\end{tabular}

\section{Results \& Discussion}

\subsection{Validation}

To validate the present numerical model, a smooth tube has been modelled and its results were compared with Dittus-Boelter equation for Nusselt number and with Blasius equation for friction factor. Comparison for Nusselt number from the present numerical model and through Dittus-Boelter equation is plotted in Fig. 6 (a). It was observed that the variation in both values are in the range of $1-7 \%$. Friction factor coefficients are also compared and are shown in Fig 6(b). Friction factor from present model has also shown similar trend as the Blasius equation. 

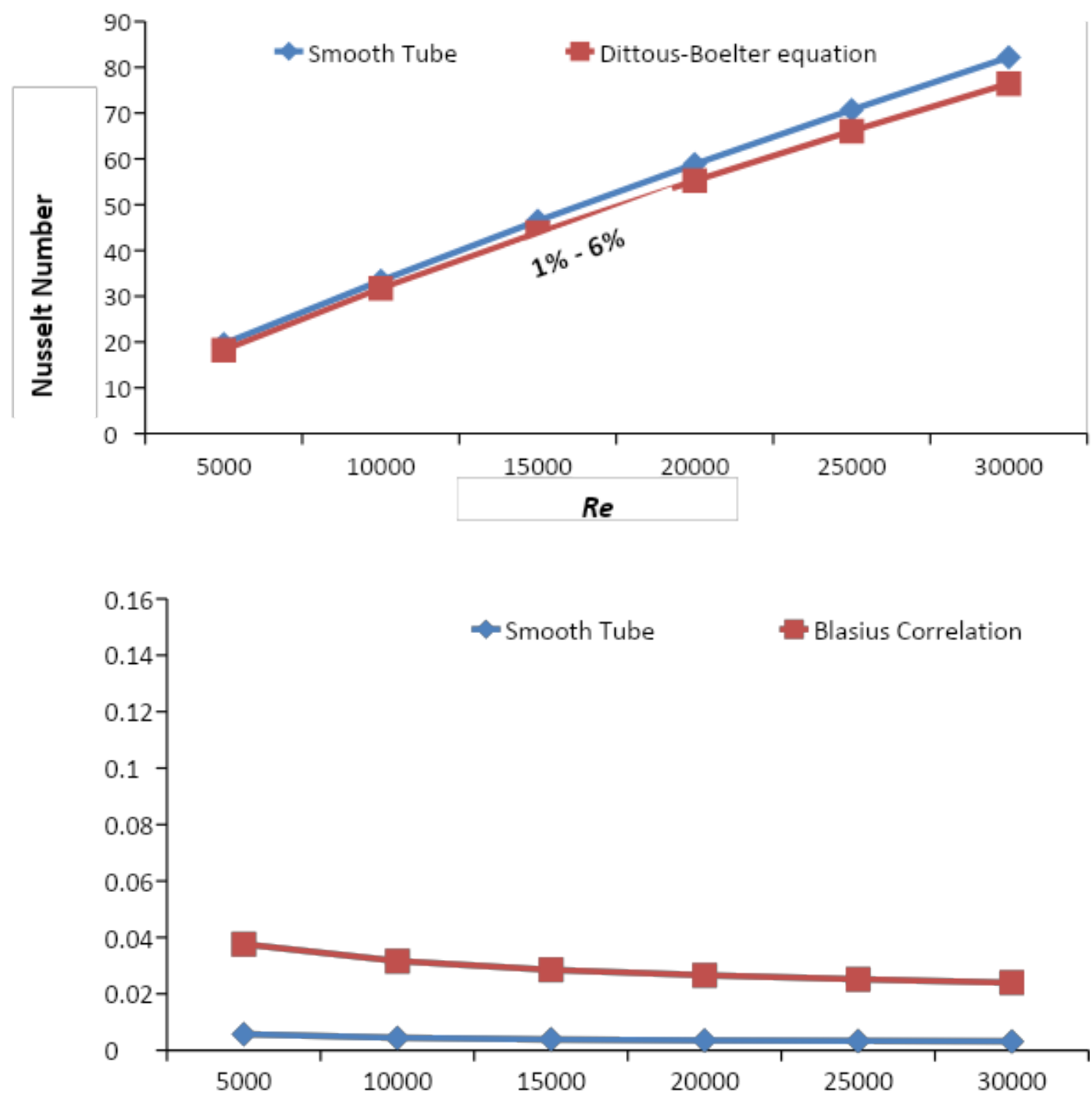

Fig 6. Comparisons plot (a) Nusselt number between present smooth tube model and Dittus-Boelter equation (b) Friction factor coefficients between present smooth tube model and

\subsection{Heat Transfer}

Blasius equation

Figure 7 indicates the comparison between the heat transfer rate as Nusselt number $(\mathrm{Nu})$ with Reynolds numbers $\operatorname{Re}(5000$ to 30000$)$ for protrusion roughness with different diameters $(\mathrm{d}=3,6$ and $9 \mathrm{~mm})$. All the results in the figure are calculated for a fixed value of pitch space of $120 \mathrm{~mm}$. It can be observed from the figure, the value of Nusselt numbers increases with increase of Reynold number for smooth pipe as well as pipe with protrusion roughness. However, heat transfer rate is significantly increased with protrusion roughness in comparison to smooth pipe. For the given condition, the maximum value of Nusselt number is obtained at $\operatorname{Re}=30000$ which is equal to $208.3692,242.3394$ and 191.1255 for roughness of 3,6 and $9 \mathrm{~mm}$, respectively. 


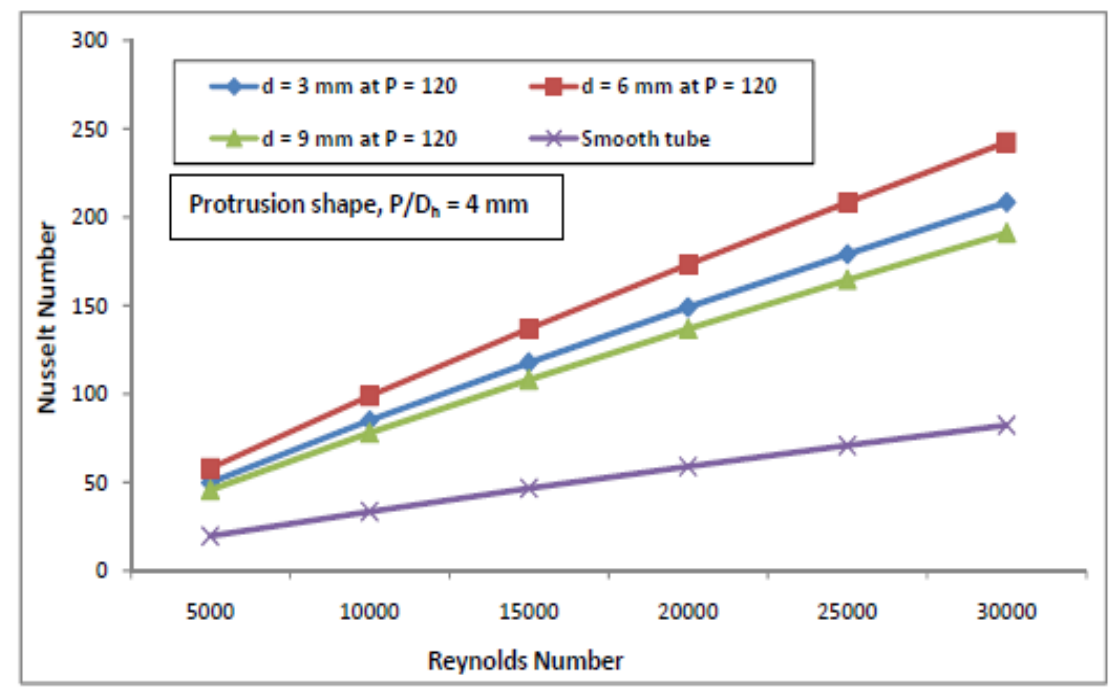

Fig 7. Variation of Nusselt numbers with Reynolds No. for protrusion roughness with different diameters and $\mathrm{P}=120 \mathrm{~mm}$.

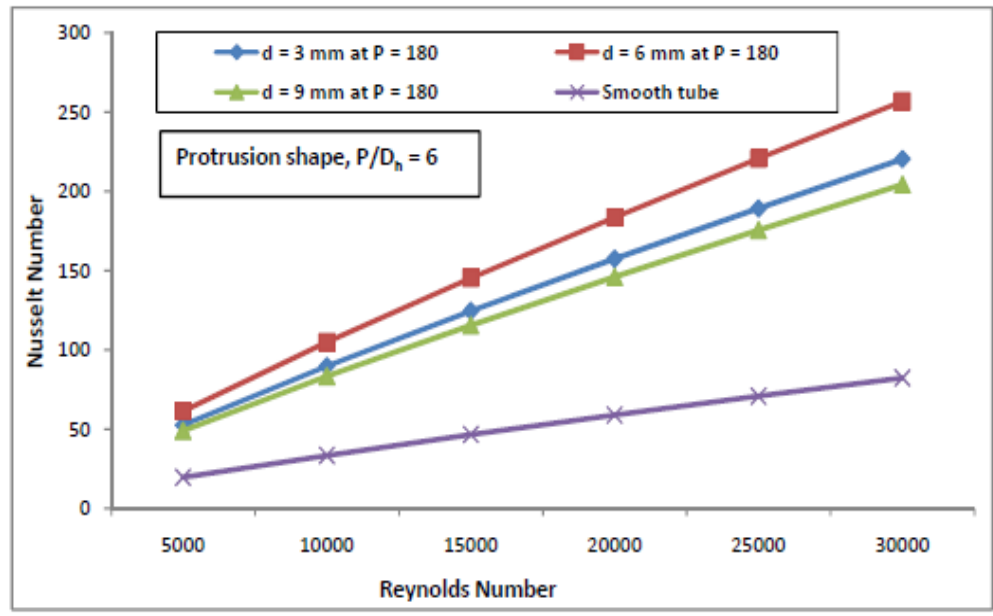

Fig. 8 Variation of Nusselt numbers with Reynolds No. for different diameters pipe with protrusion roughness and $\mathrm{P}=180 \mathrm{~mm}$.

Variation of Nusselt number ( $\mathrm{Nu}$ ) with Reynolds numbers Re (5000 to 30000 ) has been shown in Fig. 8. Figure shows the results of heat transfer in a heat exchanger pipe for protrusion roughness with different diameters $(\mathrm{d}=3,6$ and $9 \mathrm{~mm})$ and constant pitch space of $180 \mathrm{~mm}$. The results are also compared with results of heat transfer in a smooth tube. The result trends are similar as we obtain in fig. 7 . However, heat transfer has been affected with increase in pitch value. With a pitch value of $180 \mathrm{~mm}$, the maximum value of Nusselt number is increased by $5 \%, 6 \%$ and $7 \%$ for roughness diameter of 3,6 and $9 \mathrm{~mm}$, respectively, in comparison to pitch value of $120 \mathrm{~mm}$. 


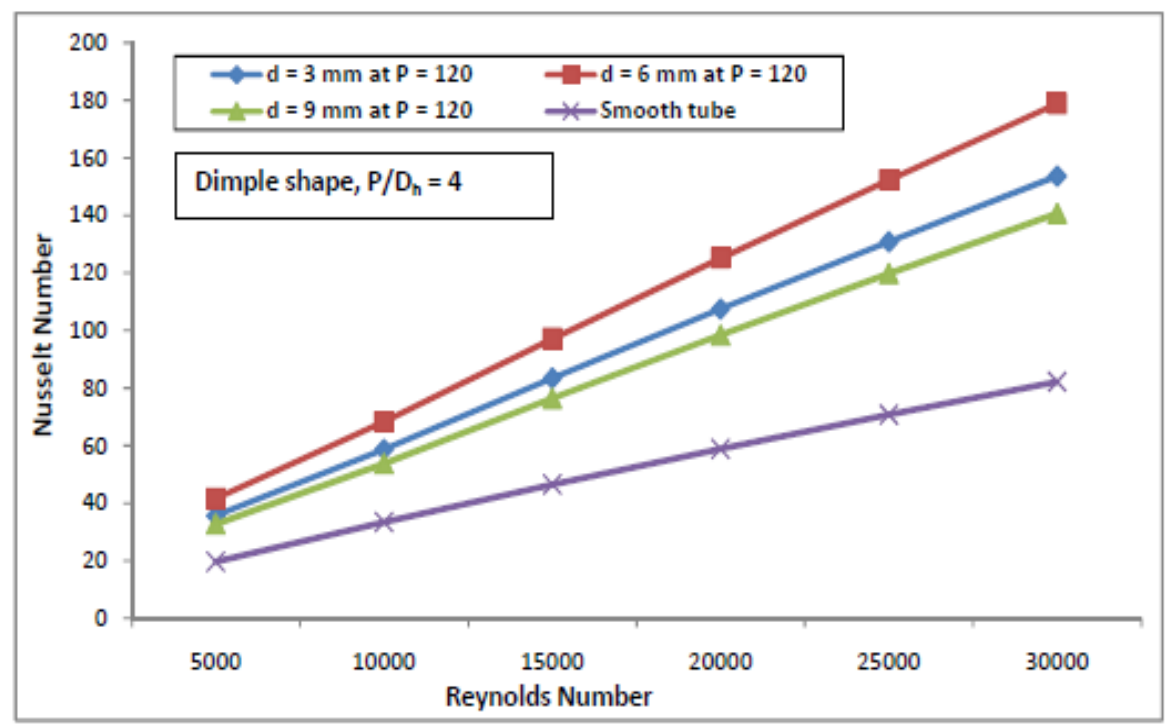

Fig 9. Variation of Nusselt number with Reynolds no for different diameters pipe with protrusion roughness and $\mathrm{P}=120 \mathrm{~mm}$.

Figure 9 shows the comparison between the heat transfer rate as Nusselt number (Nu) with Reynolds numbers $\operatorname{Re}(5000$ to 30000$)$ for dimple shape roughness insert with different diameters $(\mathrm{d}=3,6$ and $9 \mathrm{~mm})$. All the results in the figure are calculated for a fixed value of pitch space of $120 \mathrm{~mm}$. It can be observed from the figure, the value of Nusselt numbers increases with increase of Reynold number for smooth pipe as well as pipe with dimple shape roughness inserts. For the given condition, the maximum value of Nusselt number is obtained at $\operatorname{Re}=30000$ which is equal to $153.60,178.88$ and 140.71 for roughness diameters of 3,6 and $9 \mathrm{~mm}$, respectively. However, from the comparison of the results of protrusion roughness and dimple shaped roughness, it is found that heat transfer is more enhanced by the protrusion roughness. For the same working condition, the value of maximum Nusselt number is decreased by approximately $26 \%$ for all cases with dimple shaped roughness in comparison to protrusion roughness.

Variation of Nusselt number ( $\mathrm{Nu}$ ) with Reynolds numbers Re (5000 to 30000 ) has been shown in fig. 10. The figure shows the results of heat transfer in a heat exchanger pipe for dimple shaped roughness insert with different diameters $(\mathrm{d}=3,6$ and $9 \mathrm{~mm})$ and constant pitch space of $180 \mathrm{~mm}$. The results are also compared with results of heat transfer in a smooth tube. The result trends are similar as we obtain in fig. 9. However, heat transfer has been affected with increase in pitch value. With pitch value of $180 \mathrm{~mm}$, the maximum value of Nusselt number is increased by approximately $5 \%$ for roughness insert diameters, in comparison to pitch value of $120 \mathrm{~mm}$. However, these values are still low in comparison to values obtained in case of protrusion roughness. 


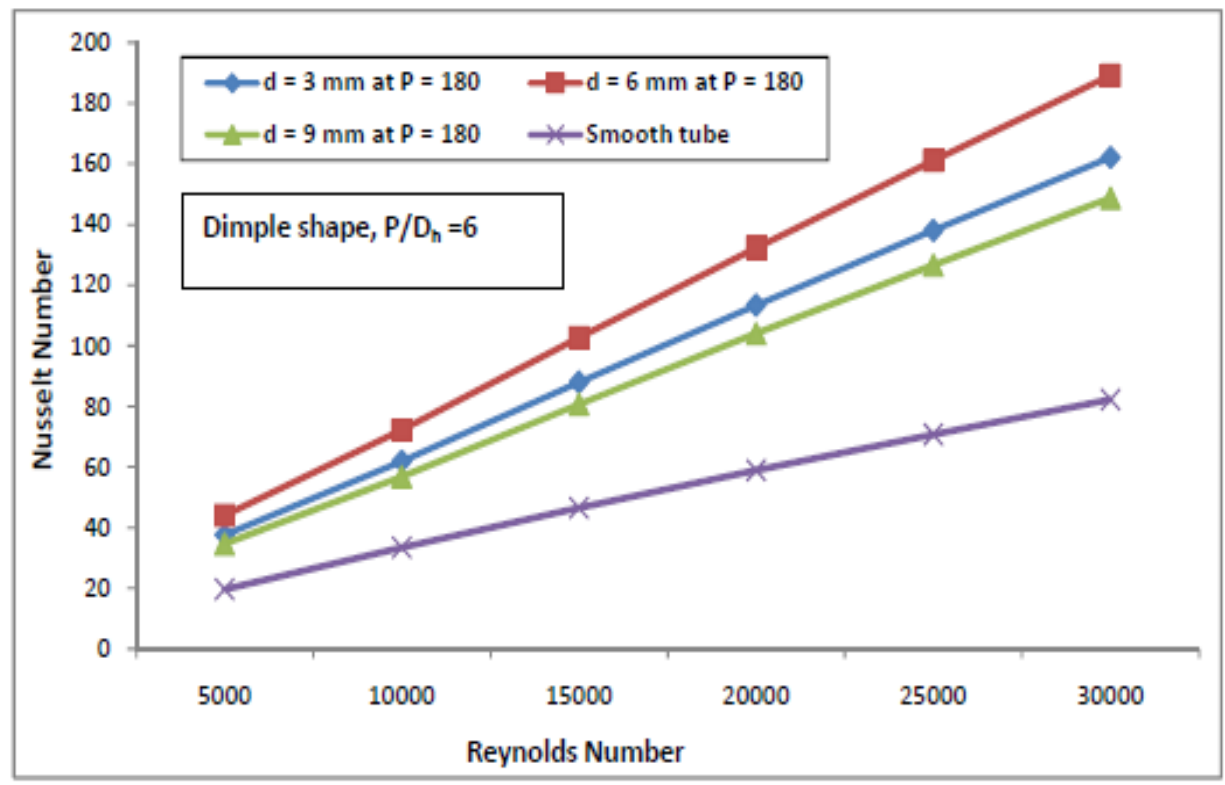

Fig 10. Variation of Nusselt number with Reynolds No for different diameters pipe with dimple roughness at $P=180 \mathrm{~mm}$.

\subsection{Friction Factor}

Figure 11 shows the variation of the Friction factor coefficient with Reynolds numbers $\operatorname{Re}(5000$ to 30000$)$ for protrusion roughness insert with different diameters ( $d=3,6$ and 9 $\mathrm{mm}$ ). All the results in the figure are taken against the fixed value of pitch space of $120 \mathrm{~mm}$. It can be observed from the figure, there is a significant difference in the Friction factor coefficient for the smooth pipe and pipes with protrusion roughness. The value of Friction factor coefficient decreases with increase of Reynold number for all the cases (smooth pipe as well as pipe with protrusion roughness). However, as the Reynold number changes from 5000 to 1000 , there is a notable change in the value of friction factor coefficient with protrusion roughness. For the given condition, the minimum value of friction factor is obtained for a flow at $\operatorname{Re}=30000$. The value of minimum friction factor is $0.0063,0.0068$, and 0.0062 for roughness insert diameter of $3 \mathrm{~mm}, 6 \mathrm{~mm}$, and $9 \mathrm{~mm}$, respectively. The results are also compared with Plain tube, the value of minimum friction factor for plain tube is 0.0031 which is significantly low in comparison to pipes with protrusion roughness. 


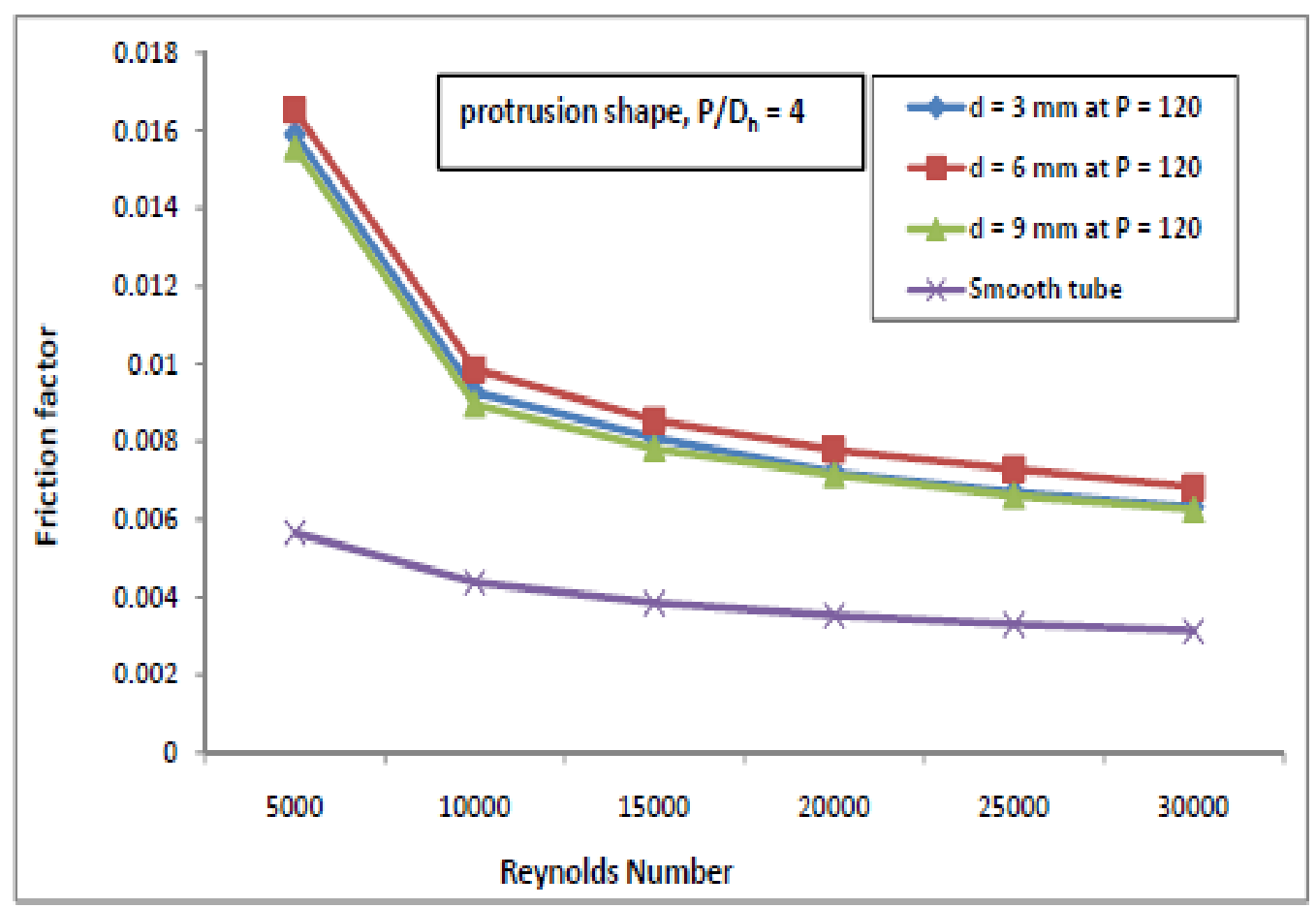

Fig 11. Variations in friction factors and Reynolds number for different diameters pipe with protrusion roughness and $\mathrm{P}=120 \mathrm{~mm}$.

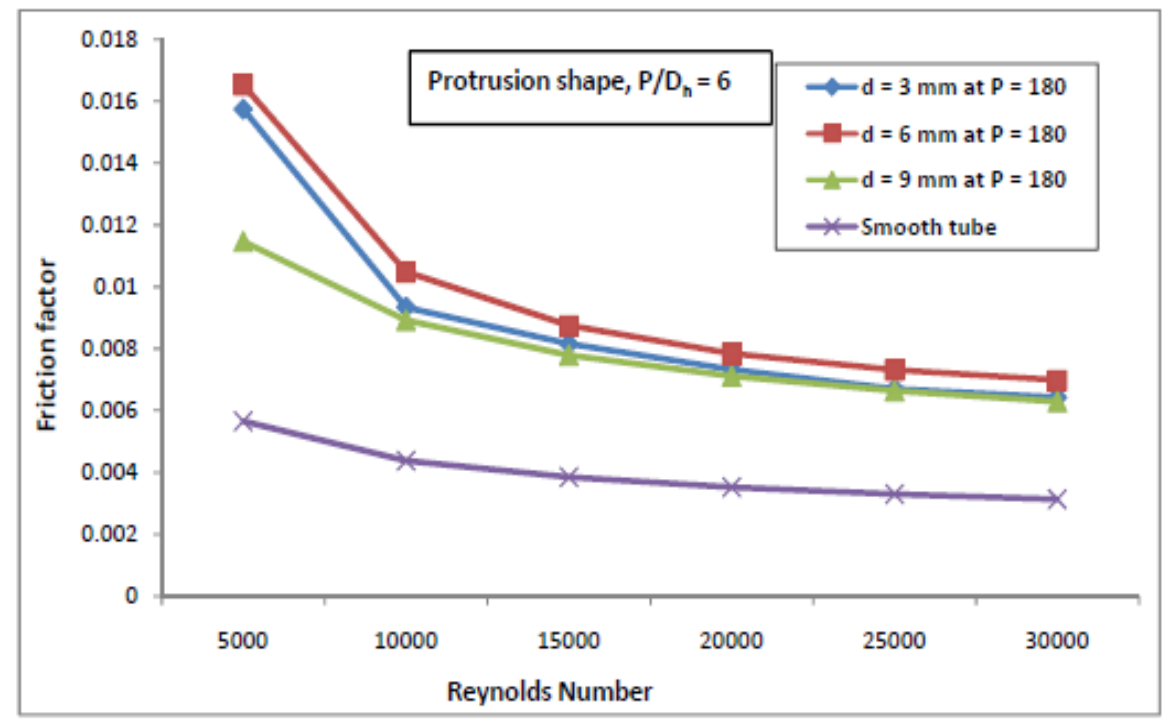

Fig 12. Variations in friction factors and Reynolds number for different diameters pipe with protrusion roughness and $P=180 \mathrm{~mm}$

Variation of the Friction factor coefficient with Reynolds numbers $\operatorname{Re}(5000$ to 30000 ) has been shown in fig. 12. The results are obtained for protrusion roughness insert with different diameters $(\mathrm{d}=3,6$ and $9 \mathrm{~mm}$ ) and a constant value of pitch space of $180 \mathrm{~mm}$. The present results are also compared with results obtained for smooth pipe. The value of the 
friction factor decreases in a similar manner with the Reynold number as we obtain in fig. 12. Apart from that, the value of minimum friction factor is little increase with increase in pitch space from $120 \mathrm{~mm}$ to $180 \mathrm{~mm}$.

The minimum friction is $0.0064,0.0069$, and 0.0062 at insert diameters of 3,6 and $9 \mathrm{~mm}$, respectively.

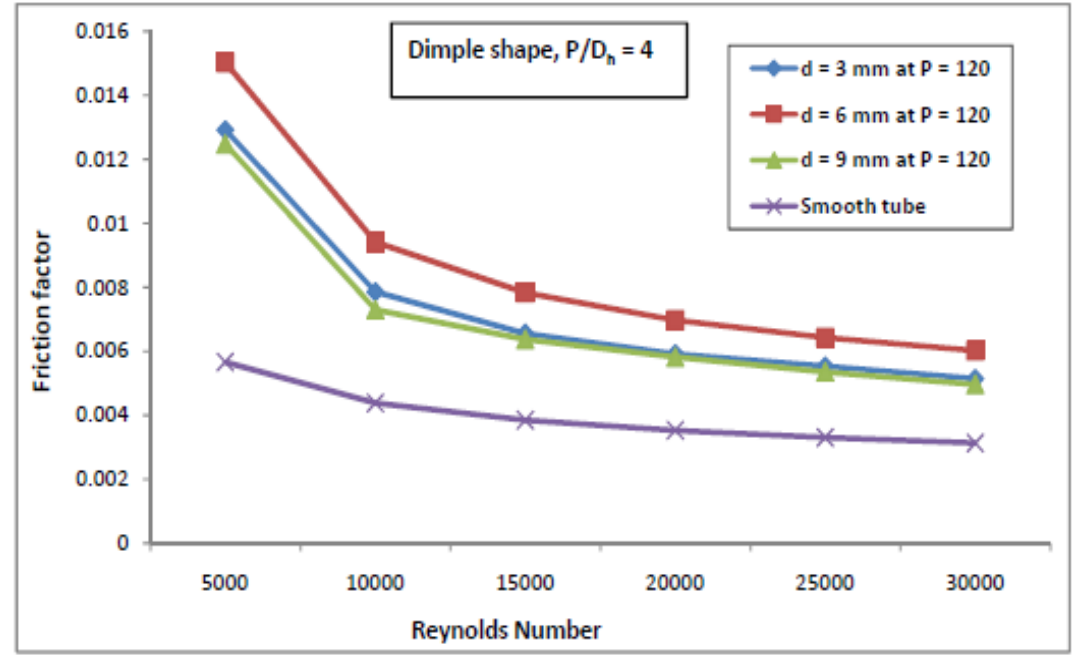

Fig 13. Variations in friction factors and Reynolds number for different diameters pipe with dimple shaped roughness and $P=120 \mathrm{~mm}$.

Figure 13 shows the variation of the Friction factor coefficient with Reynolds numbers $\operatorname{Re}(5000$ to 30000$)$ for dimple shaped roughness insert with different diameters ( $d=3,6$ and $9 \mathrm{~mm}$ ). All the results in the figure are taken against the fixed value of pitch space of $120 \mathrm{~mm}$. It can be seen in the figure that, friction factor decreases with the Reynold number. The minimum friction is $0.0051,0.0060$, and 0.0049 at insert diameter of 3,6 and $9 \mathrm{~mm}$, respectively. From the comparison of the results with protrusion roughness pipe for a given condition, it can be concluded that the value of friction factor is approximately low by $19 \%$ with dimple shaped roughness insert pipe. 


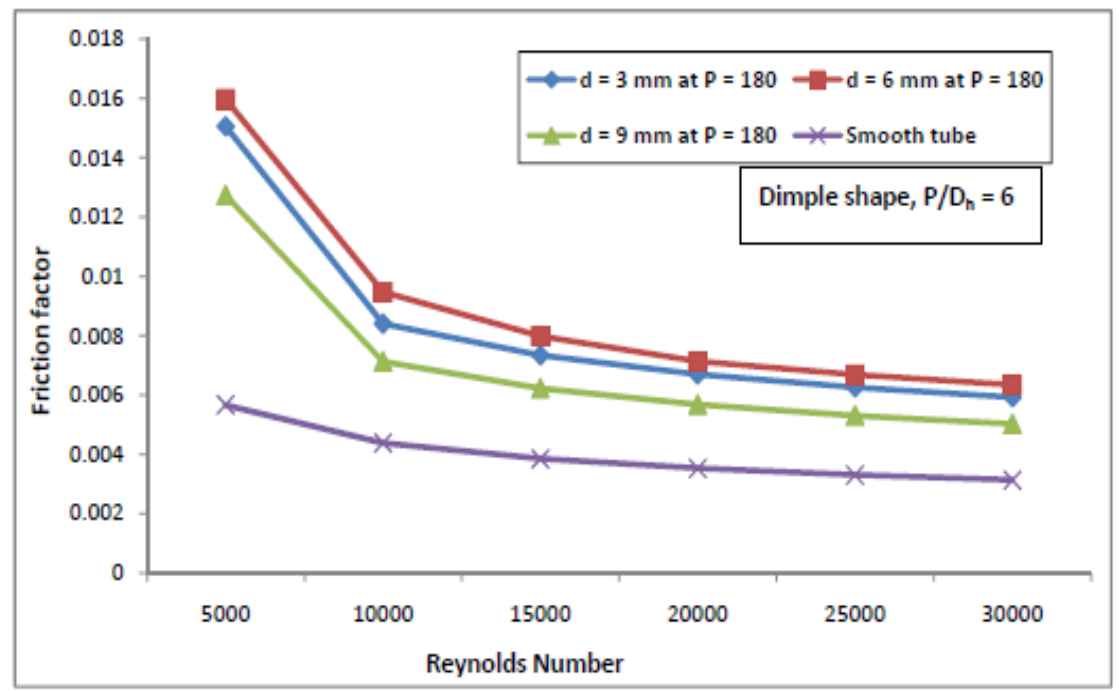

Fig. 14 Variations in friction factors and Reynolds number for different diameters pipe with dimple shaped roughness and $p=180 \mathrm{~mm}$.

Variation of the Friction factor coefficient with Reynolds numbers $\operatorname{Re}(5000$ to 30000 ) has been shown in fig. 14. The results are obtained for dimple shaped roughness insert with different diameters $(\mathrm{d}=3,6$ and $9 \mathrm{~mm}$ ) and a constant value of pitch space of $180 \mathrm{~mm}$. The Fig. 4.29 shows the minimum friction factors are $0.0059,0.0063$, and 0.0050 are observed at $d$ $=3 \mathrm{~mm}, 6 \mathrm{~mm}$, and $9 \mathrm{~mm}$ respectively.

\subsection{Fluid flow characteristics}

The velocity contours have been plotted at $\mathrm{Re}=30000$ for different configurations to comprehend the flow physics. Figure 15 shows the fluid flow through the tube with a zoomed view of a single conical insert. Flow remains undisturbed in the center of the conical insert while flow gets deflected at the wall of the insert.

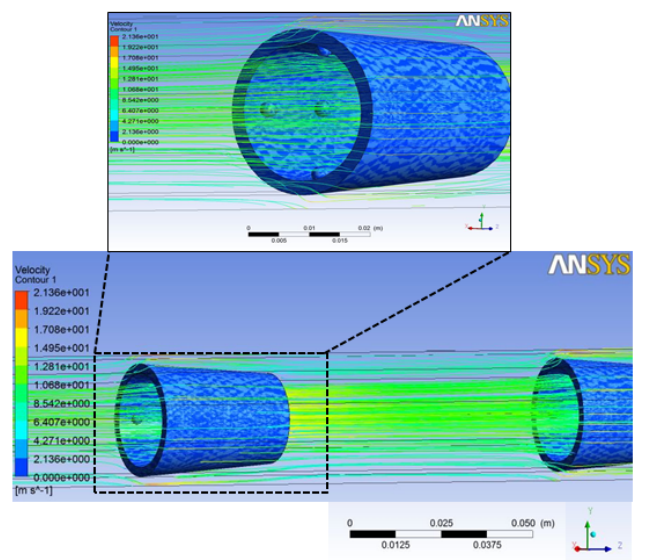

Fig 15. Velocity contour through tube with conical insert

Figure 16 shows the variation in velocity contours due to variation in dimple diameter. The velocity contours of different dimple diameters appear to be the same. Moreover, the flow 
in protrusion affects the vortices and vortex generation. The dimple diameter of $6 \mathrm{~mm}$ has shown most favorable flow characteristics compared to $d=3 \mathrm{~mm}$ and $\mathrm{d}=9 \mathrm{~mm}$.

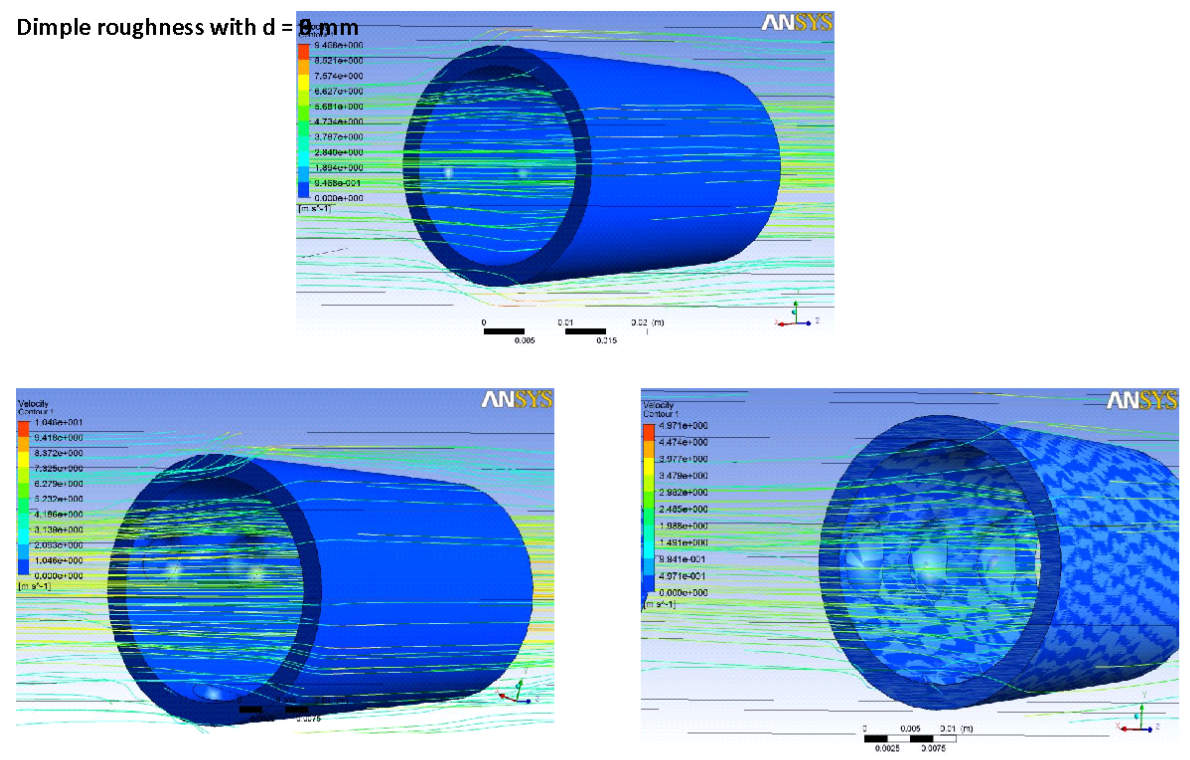

Fig 16. Velocity contour for different dimple roughness in conical insert

The variation in flow contour for different protrusion meters in conical insert was shown in Fig. 17. It is seen that when diameter is very small i.e. $\mathrm{d}=3 \mathrm{~mm}$, flow behavior changes near the wall but has very less influence in the middle. As diameter increases to 6 $\mathrm{mm}$, the flow pattern changes throughout the insert. Due to this favorable flow characteristic, this configuration has shown higher thermal performance. However, with further increase in protrusion diameter the flow gets adversely affected and leads to lower performance.

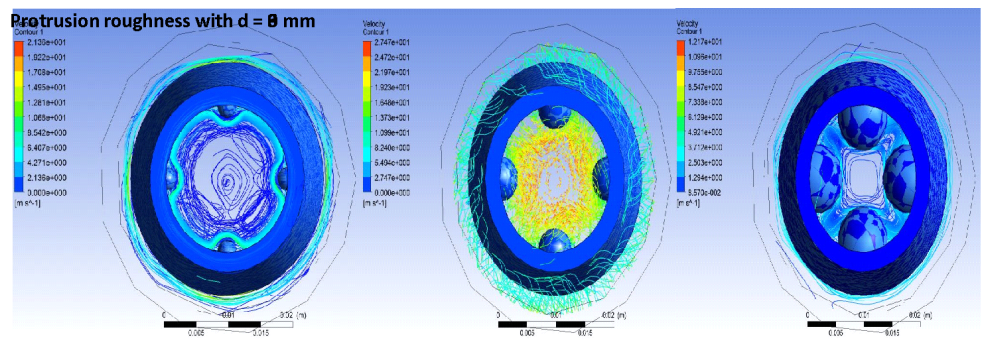

Fig 17. Velocity contour for different protrusion roughness in conical insert

\section{Future Scope}

Heat transfer augmentation in heat exchanger using passive structure has been studied rigorously and still there are many innovative designs which can be implemented. The present work can be extended by modifying different inserts in the heat exchanger tubes. Moreover, performance of the present system can be enhanced with use of nanofluids, PCM slurries, etc. Furthermore, experimental investigation can also be performed to study the influence of various geometrical and operational parameters. 


\section{Conclusion}

There are various methods used for heat transfer augmentation of heat exchangers. Among them, the use of insert like twisted wire, conical insert in heat exchanger tube is mostly used. In present work, conical insert has been used with different diameter of dimple and protrusion roughness. The thermo-hydraulic performances have been investigated for a range of Reynold number (5000-30000). Using ANSYS FLUENT commercial code, effect of diameter were seen on Nusselt number and friction factor coefficients. On the basis of results following conclusions are drawn:

1. It is observed that the $k-\varepsilon$ standard model could provide results in acceptable range in double tube heat exchangers.

2. It is found that with the increase in Reynold number, Nusselt number increases while friction factor coefficients decrease regardless of dimple and protrusion diameters.

3. With increase in dimple and protrusion diameter, thermal performance firstly increases and then afterwards it decreases irrespective of Reynold number.

4. For both protrusion and dimple roughness, diameter of $6 \mathrm{~mm}$ has shown favorable flow characteristics which leads to enhanced thermal performance.

\section{References}

[1] Rashidi S, Hormozi F, Sundén B, Mahian O. Energy saving in thermal energy systems using dimpled surface technology-A review on mechanisms and applications. Applied Energy. 2019, 15;250:1491-547.

[2] Bhandari P, Varshney L, Bisht VS. Numerical analysis of hybrid solar water heating system using wire screen packed solar air heater. In1st International conference on new frontiers in engineering, science \& technology 2018 (Vol. 1, pp. 415-1422).

[3] Varshney L, Bhandari P, Bisht VS. Performance Evaluation of Hybrid Solar Water Heating System Using Wire Screen Packed Solar Air Heater. Int. Journal of Engineering Research and Application (IJERA). 2014:311-6.

[4] Mohammed HA, Abuobeida IA, Vuthaluru HB, Liu S. Two-phase forced convection of nanofluids flow in circular tubes using convergent and divergent conical rings inserts. International Communications in Heat and Mass Transfer. 2019,101:10-20.

[5] Kumar N, Singh P, Redhewal AK, Bhandari P. A review on nanofluids applications for heat transfer in micro-channels. Procedia Engineering. 2015,127:1197-202.

[6] Thianpong C, Eiamsa-Ard P, Eiamsa-Ard S. Heat transfer and thermal performance characteristics of heat exchanger tube fitted with perforated twisted-tapes. Heat and Mass Transfer. 2012, 48(6):881-92.

[7] Eiamsa-ard, S.: Study on thermal and fluid flow characteristics in turbulent channel flows with multiple twisted tape vortex generators. International Communications in Heat and Mass Transfer, 31, 644-651 (2010).

[8] Murugesan, P.A., Mayilsamy, K.B., Suresh, S.C., Srinivasan, P. S. S.: Heat Transfer And Pressure Drop Characteristics Of Turbulent Flow in a tube fitted with Trapezoidal-Cut Twisted Tape Insert, International Journal Of Academic Research,1, LCC: TJ255-265 UDC: 621.839(2009).

[9] Murugesan, P.A., Mayilsamy, K.B., Suresh, S.C.: Heat Transfer and Friction Factor in a Tube Equipped with U-cut Twisted Tape Insert. Jordan Journal of Mechanical and Industrial Engineering, 5(6),559-565(2011).

[10] Promvonge, P.:Thermal augmentation in circular tube with twisted tape and wire coil turbulators. Energy Conversion and Management, 49, 2949-2955, (2008). 
[11] Eiamsa-ard, S.A., Nivesrangsan, P. A., Chokphoemphun, S.B., Promvonge, P.: Influence of combined non-uniform wire coil and twisted tape inserts on thermal performance characteristics. International Communications in Heat and Mass Transfer, 37, 850-856(2010).

[12] Arulprakasajothi, M., Elangovan, K., Hema Chandra Reddy, K., Suresh, S.: Experimental investigation on heat transfer effect on conical strip inserts in a circular tube under laminar flow. Front. Energy, 10: 136, (2016).

[13] Durmus, A.: Heat transfer and exergy loss in cut out conical turbulators. Energy Convers. Manage. 45, 785-796 (2004).

[14] P. Promvonge, P.,Eiamsa-ard,S.: Heat transfer behaviors in a tube with combined conical-ring and twisted-tape insert. Int. Commun. Heat Mass Transfer 34, 849-859 (2007).

[15] Promvonge, P.: Heat transfer behaviors in round tube with conical ring inserts, Energy Conversion and Management 49, 8 - 15, (2008).

[16] K. Nanan a, C. Thianpong b, P. Promvonge b, S. Eiamsa-ard, Investigation of heat transfer enhancement by perforated helical twisted-tapes, International Communications in Heat and Mass Transfer 52 (2014) 106-112

[17] Y. He, L. Liu, P. Li, L. Ma, Experimental study on Heat transfer enhancement characteristics of tube with cross hollow twisted tape inserts, Applied Thermal Engineering (2017),

[18] B. P. Singh, V. S. Bisht, P. Bhandari, Numerical Study of Heat Exchanger Having Protrusion and Dimple Roughened Conical Ring Inserts, in Advances in Fluid and Thermal Engineering, Sikarwar B.S., Sundén B., Wang Q. (eds), Lecture Notes in Mechanical Engineering. Eds., Singapore: Springer Publishing pp. 151-161, 2021 